\title{
Review
}

\section{Cysticercosis in Madagascar}

\author{
Jean-François Carod ${ }^{1}$, Pierre Dorny ${ }^{2}$ \\ ${ }^{1}$ Clinical Laboratory, West Guiana Hospital Center, Saint-Laurent-du-Maroni, French Guiana \\ ${ }^{2}$ Unit of Veterinary Helminthology, Department of Biomedical Sciences, Institute of Tropical Medicine, Antwerp, \\ Belgium
}

\begin{abstract}
Introduction: Cysticercosis (CC) is the most common parasitic disease of the central nervous system. It is endemic in most developing countries where pigs are raised and consumed. An overview of all available data of this parasite in Madagascar is lacking.

Methodology: We conducted a literature review, collecting information on published and available literature about cysticercosis in Madagascar between January 1st, 1990 and June 30th, 2020.

Results: Out of 858 publications; 61 were included, issued from peer-review indexed journals, non-indexed journals, books, Ministry reports and press releases. In Madagascar, porcine cysticercosis has been reported since 1901; human cysticercosis is highly prevalent with an overall estimated seroprevalence between 7 and 21\%. Serological analysis is based on Enzyme-Linked Immunosorbent Assay (ELISA) and Enzymelinked immunoelectrotransfer blot techniques (EITB) for confirmative testing. Neurocysticercosis (NCC) is the most common pattern of cysticercosis in Madagascar and it is reponsible for pediatric morbidity causing more than $50 \%$ of epilepsy cases. Though CT-Scan is now available and tends to be considered the gold standard for NCC diagnosis, it remains unaffordable for most Malagasy patients and implies the proposal of a diagnostic algorithm for physicians.

Conclusions: Our review has revealed that human taeniasis and bovine cysticercosis is a considerable burden in Madagascar. A national control program has been developed aiming to decrease the seroprevalence rate from 16 to $10 \%$ in 2015 . The aim of the country is now to implement a CC control and elimination program. Meanwhile, some massive cysticercosis screenings have been conducted in the capital Antananarivo to drive people's attention on this widespread infection.
\end{abstract}

Key words: Neurocysticercosis; Madagascar; Taenia solium; review.

J Infect Dev Ctries 2020; 14(9):931-942. doi:10.3855/jidc.13450

(Received 12 July 2020 - Accepted 24 August 2020)

Copyright $(C 2020$ Carod et al. This is an open-access article distributed under the Creative Commons Attribution License, which permits unrestricted use, distribution, and reproduction in any medium, provided the original work is properly cited.

\section{Introduction}

Cysticercosis (CC) of the central nervous system (neurocysticercosis or NCC) is caused by the larval stage (cysticercus) of the pork tapeworm Taenia solium. When people eat undercooked pork containing viable cysticerci, these develop into an intestinal tapeworm infection. Human beings can also become dead end intermediate hosts by ingesting $T$. solium eggs shed in the faeces of human carriers of the adult parasite. These eggs develop into cysticerci, which establish mostly into muscles causing cysticercosis, and the central nervous system causing neurocysticercosis. Brain infection can cause seizures and many other neurological symptoms. NCC is a major cause of epilepsy in developing countries. It is the most important neurological disease of parasitic origin in humans $[1,2]$. The pathogenesis of NCC is unclear but symptoms seem to be correlated to the stage, the number and the location of the cysts. Starting as a viable entity, the cyst gradually degenerates to end as a calcified granule. Seizures seem to appear mainly at the degenerating and calcified stage but treatment is efficient on living cysts. Human cysticercosis is endemic in the Andean area of South America, Brazil, Central America and Mexico, China, the Indian subcontinent, South-East Asia; and sub-Saharan Africa, including Madagascar [3]. In Madagascar, most of the available literature on $\mathrm{CC}$ has been published in French in local journals. The objective of this review was to collect all available data on cysticercosis in Madagascar up to June 2020 and to synthesize the points of interest.

\section{Methodology}

A review of reports, information and indexed literature on cysticercosis and $T$. solium pertaining to Madagascar and published in the period 01/01/1990$06 / 30 / 2020$ has been conducted. The data analysis focused on epidemiological data, clinical data, diagnosis, therapeutical and public health aspects for both human and porcine cysticercosis. The 
investigation covered all regions of the Madagascar island.

\section{Search}

The following search strategy in PubMed (http://www.ncbi.nlm.nih.gov/pubmed/), and Science direct (sciencedirect.com) was adopted: (taenia OR cysticercosis OR cysticercose) AND (Madagascar) AND ("1990/01/01" to "2020/06/30"). Moreover, additional published and unpublished studies were included as well as data or policies from the Ministry of Health $(\mathrm{MoH})$ and the Ministry of Agriculture of Madagascar. In addition, all reports released in the daily Malagasy press available online during the same period were screened and analysed.

\section{Selection}

The authors screened articles found by electronic search and evaluated their appropriateness based on title and abstract, established according to the criteria. Exclusion criteria were: 1) studies considering another agent (for example Taenia saginata or Echinococcus spp.), 2) reviews, editorials or letters without original data, and 3) duplicated data. If the recordings of the admissibility could not be ascertained according to the abstract and title only, the full text was analyzed to exclude or include the document. Manuscripts written in English, French and Malagasy were included.

\section{Extraction}

Data from epidemiological studies were summarized, while data from case reports and case series were classified according to the del Brutto criteria [2]. Press releases were extracted when judged scientifically relevant.

\section{Results}

Out of 858 publications; 61 were included, issued from peer-review indexed journals, non-indexed journals, books, Ministry reports and press releases. Results have been classified in the following categories: epidemiology, diagnosis, clinical features, prevention, and policy.

\section{Epidemiology of cysticercosis in Madagascar Overall}

With an area of $587,041 \mathrm{~km}^{2}$, Madagascar is the fourth largest island in the world (Figure 1). It is located $450 \mathrm{~km}(280 \mathrm{mi})$ east of the coast of Mozambique. The island has a population of more than 22 million, of which $10 \%$ are living in the capital Antananarivo. The island has a tropical climate with different climatic zones: rain clouds originating from over the Indian Ocean discharge most of their moisture over the island's eastern coast, resulting in heavy precipitations supporting the area's rain forest ecosystem. The central highlands are drier and cooler while the west is drier and hot, a semi-arid/arid climate prevails in the southwest and southern part of the island.

The people of Madagascar are known as Malagasy and represent 18 different ethnic groups of African and Southeast Asian origin [4]. Nearly half of the Malagasy population is under the age of 15 years and suffers from extreme poverty, very low hygiene standards and lack of education. Madagascar also continues to face serious health problems. Acute respiratory infection, diarrheal diseases, fever, and high levels of acute and chronic malnutrition in children under 3 years of age exemplify the country's disease burden.

With $1,380,250$ pigs in more than 500,000 herds, the pig population in Madagascar is the seventh largest in Africa. Most farmers are smallholders who own 2.4 pigs/herd, on average. Pig breeding is mainly

Figure 1. Map of Madagascar indicating the major cities, roads and altitude.

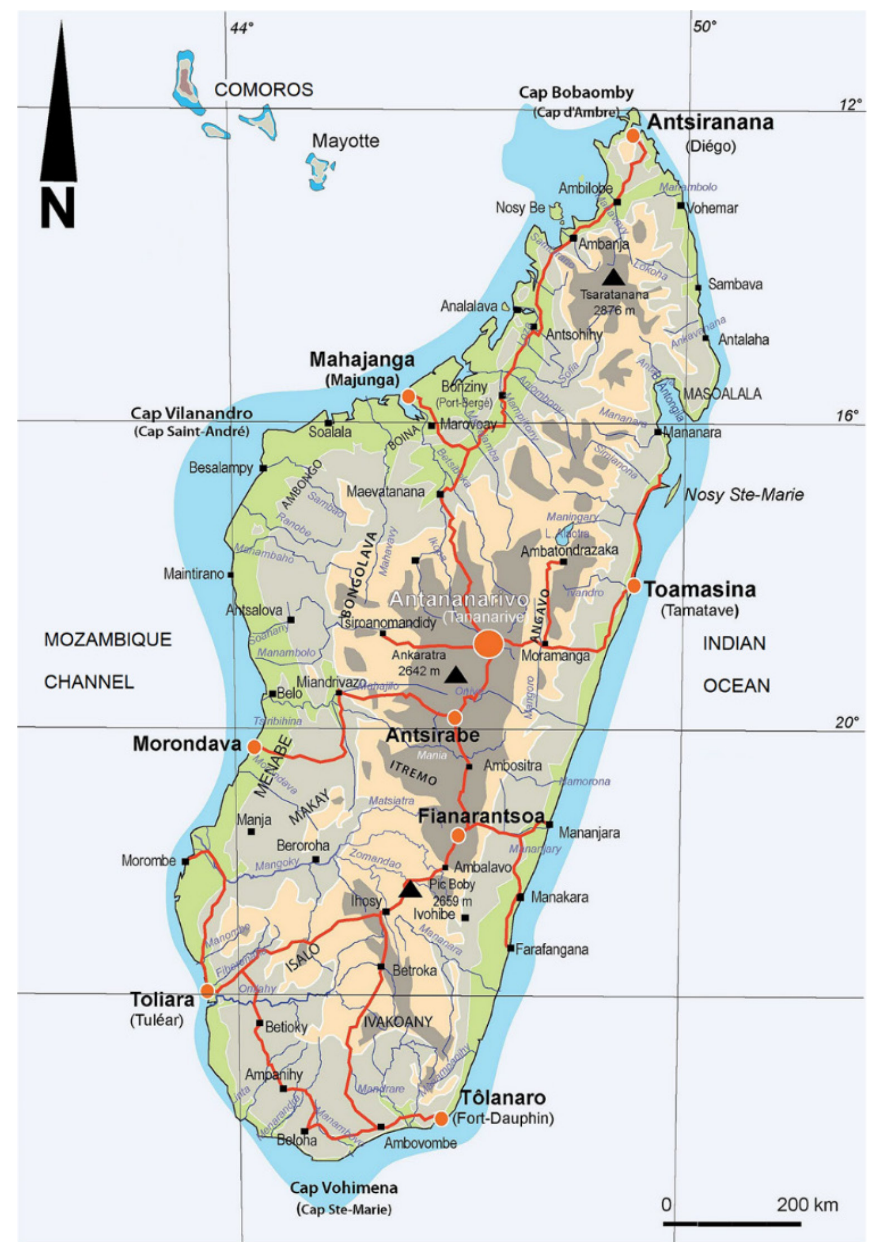


concentrated in the highlands which holds $70 \%$ of the total pig population. In villages, pigs roam freely during the daytime seeking food. The pork meat chain is generally informal and most owners are reluctant to embrace official recommendations concerning good rearing practices [5].

\section{Porcine cysticercosis}

Cysticercosis and epilepsy are part of the history of Madagascar as described in "the possessed" of the Queen Ranavalona [6].

Porcine cysticercosis was first described in 1901. In 1926, meat inspectors operating in Malagasy slaughterhouses observed an infection rate of the swine carcasses of between 4 to $20 \%$. The infection rate was found to be between 8 and 24\% in 1958 and between 3 and $14 \%$ in 1961, depending to the geographical area [7]. Since 1961, illegal slaughtering has grown considerably (nearly $100 \%$ of the slaughtered pigs). The overall apparent prevalence of cystercercosis was estimated at $4.6 \%$ [4.2 - 5.0\%]. The corrected overall prevalence defined as the estimated prevalence after accounting for the sensitivity of meat inspection was 21.03\% (19.18- 22.87). A recent survey, in Anosizato and Ankadindratombo districts of Antananarivo estimated a prevalence of swine cysticercosis of $4.6 \%$ [4.2 - 5.0\%] based on meat inspection [7] (Figure 2). Risk factors associated with the incidence were: the pig breed, the slaughterhouse site and the area of origin of the pig (highest prevalence in Sofia and Diana provinces north-east of Madagascar [5,7]. The authors stated that the prevalence rate found was eight times higher than officially reported.
Figure 2. Cysticercosis cysts in a pig's heart (Pasteur Institute of Madagascar, 2009).

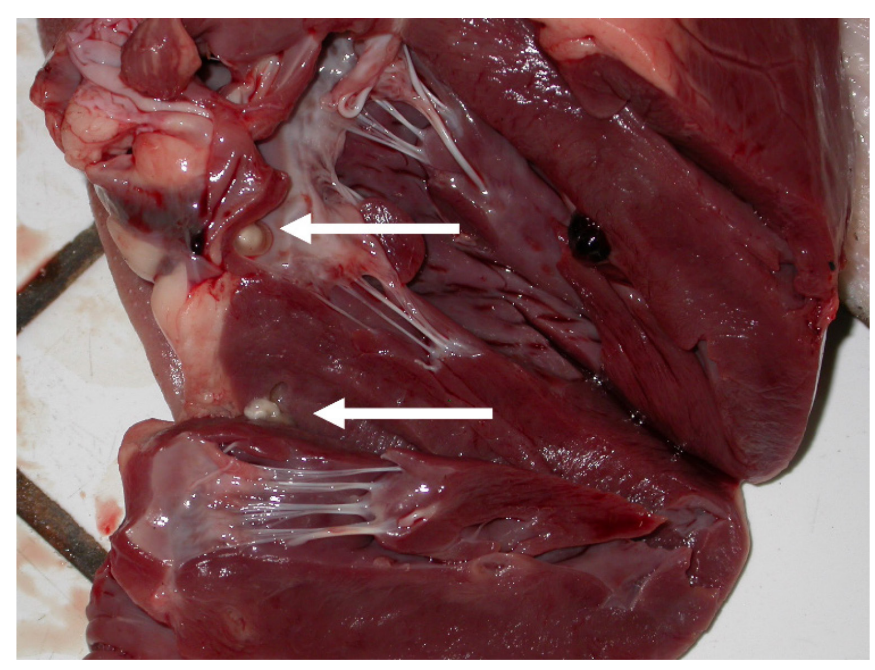

Molecular studies of cysticerci collected from pigs in Madagascar demonstrated that Asian and African/Latin American genotypes are indiginous on the island $[8,9]$. A recent study shows that the major mitochondrial haplotype of T. solium in Madagascar is closely related to that from the Indian Subcontinent [4]. There is also evidence of nuclear-mitochondrial discordance in single tapeworms in the country, indicating cross-fertilization between the two lineages of T. solium [4]. Analyses of genetic and geographic populations of T. solium in Madagascar will shed light on an apparently rapid evolution of this organism driven by recent $(<2,000$ years) human migrations, following geographic isolation for over ten thousand years.

Table 1. Characteristics of the main sero-epidemiological surveys on cysticercosis in Madagascar.

\begin{tabular}{|c|c|c|c|c|c|c|c|c|}
\hline Year & Area & $\begin{array}{c}\text { Epidemiological } \\
\text { method }\end{array}$ & $\begin{array}{c}\text { Laboratory } \\
\text { tests }\end{array}$ & $\begin{array}{c}\text { Targeted } \\
\text { population }\end{array}$ & $\begin{array}{l}\text { Samples } \\
\text { number }\end{array}$ & $\begin{array}{l}\text { Active CC } \\
\text { prevalence }\end{array}$ & CI 95\% & Ref. \\
\hline 1992 & Mahajanga & Cluster sampling & $\begin{array}{c}\text { ELISA } \pm \\
\text { EITB* }\end{array}$ & $>1$ year old & 626 & $19 \%$ & $15.8-22.7$ & [11] \\
\hline 1994 & $\begin{array}{l}\text { Antana-narivo } \\
\text { Toamasina }\end{array}$ & Cluster sampling & $\begin{array}{l}\text { ELISA } \pm \\
\text { EITB* }\end{array}$ & $>1$ year old & 626 & $7.1 \%$ & $4.9-10.4$ & [12] \\
\hline 1996 & Ambositra & Cluster sampling & $\begin{array}{l}\text { ELISA } \pm \\
\text { EITB* }^{*}\end{array}$ & $>1$ year old & 793 & $8.0 \%$ & $6.0-10.5$ & [12] \\
\hline 1999 & Mahajanga & Cluster sampling & $\begin{array}{l}\text { ELISA } \pm \\
\text { EITB* }^{*}\end{array}$ & $>2$ year old & 930 & $16.4 \%$ & $13.6-19.7$ & [12] \\
\hline 1997 & Ihosy & exhaustive & $\begin{array}{l}\text { ELISA } \pm \\
\text { EITB* }^{*}\end{array}$ & $>1$ year old & 443 & $21.2 \%$ & $17.6-25.4$ & [12] \\
\hline 1999 & Mahasolo & exhaustive & $\begin{array}{l}\text { ELISA } \pm \\
\text { EITB* }^{*}\end{array}$ & $>1$ year old & 855 & $11.6 \%$ & $9.6-13.9$ & [12] \\
\hline 1999 & Ambositra & exhaustive & $\begin{array}{l}\text { ELISA } \pm \\
\text { EITB* }\end{array}$ & $>5$ year old & 728 & $17.0 \%$ & $14.4-20.0$ & [12] \\
\hline 2017 & Ifanadiana & Sampling & ELISA \pm EITB & $>5$ year & 543 & $\begin{array}{c}30,6 \% \text { (ELISA), } \\
2,2 \% \text { (EITB) }\end{array}$ & ND & [15] \\
\hline
\end{tabular}

* Samples positive with ELISA were tested by Enzyme-linked Immuno-Electro Transfer Blot (EITB). The presence of the 13 or/and $14 \mathrm{kDa}$ bands was considered as highly suggestive of active cysticercosis. 
Human cysticercosis

The first epidemiological data on human cysticercosis were reported by the Pasteur Institute (IPM) of Madagascar. A prevalence based on histological analysis of $0.25 \%$ was found among 63,488 samples collected and analyzed at the pathology laboratory from 1954 to 1984. However, histological reports may not reflect the country $\mathrm{CC}$ seroprevalence [6]. A survey in 1992 in the harbour of Mahajanga focused on seroprevalence data and on a serodiagnostic study. The overall CC seroprevalence was 14.21\% (26/183) [10]. Asymptomatic outpatients showed a seroprevalence of $5.76 \%$ (8/139) vs. $31.85 \%$ (107/336) for symptomatic outpatients. In July 1999, a new seroepidemiological survey was conducted in the same city of Mahajanga, with the aim to assessing the prevalence of cysticercosis in the general population of the city. Blood specimens were collected from a randomized sample of 626 individuals older than 2 years old. Enzyme-Linked Immunosorbent Assay (ELISA) and confirmatory Enzyme-linked immunoelectrotransfer blot techniques (EITB) were used to measure $\mathrm{CC}$ antibodies. The overall prevalence by ELISA was 19\% [95\% CI: 15.8-22.7]. Among ELISA positive cases, $87 \%$ were found positive by EITB [11]. A multi-centric study including 4,375 serum samples was conducted from 1994 until 1999 aiming at determinating the seroprevalence of cysticercosis in different provinces of Madagascar [12]. The study confirmed that cysticercosis is highly prevalent on the island, and that a significant difference of seroprevalence exists between the different provinces: from $10 \%$ in the coastal regions (Mahajanga and Toamasina) to $20 \%$ in the central regions (Ihosy, Ambositra and Mahasolo) (Table 1, Figure 1). Ampefy area showed in 1999 a seroprevalence of 16\% [13] and recently a survey in Alakamisy Ambohimaha, a rural town of the highlands, showed 12\% [CI95: 6,8- 17,2] seropositivity [14]. It has also been noted that CC may occur at any age and that it is equally distributed in urban and rural areas. However, it is more frequently detected in women than in men $[12,14]$.

A recent study conducted between 2016 and 2017 focused on the district of Ifanadiana, located at the level of a geographical and cultural divide of the big island. The eggs of Taenia spp. were detected in $2.2 \%$ of the samples. By ELISA, the prevalence of antibodies (IgG) against $T$. solium cysticercus membrane glycoproteins was $30.6 \%$ (95\% CI: 26.7-34.4) but only $2.2 \%$ were confirmed by EITB. This difference again emphasizes the difficulties of interpreting the figures according to the performance of the tools used [15].
Data collected by the Department for the Fight against Bilharzia and Cysticercosis during 2001-2003 in Hospitals of Antananarivo showed that $12 \%$ of the serum samples were found positive for Cysticercosis and that $43.5 \%$ of inpatients of the the Neurology Unit of the Military Hospital Soavinandriana in Antananarivo were suspected cases of neurocysticercosis (Ministry of Health, Family Planning and Social Protection of Madagascar, 2005). Between 2002 and 2004, the Malagasy Department for the Fight against Endemic Diseases reported an average of 250 annual cases of neurocysticercosis that were diagnosed and treated in the Medical Intensive Care Unit of the Hospital Ravoahangy Joseph Andrianavalona [11,12]. Living under the same conditions as the local population exposes foreigners to cysticercosis. Among 73 Peace Corps volunteers (median age, 24 years), who underwent EITB serologic testing for cysticercosis, $6(8.2 \%)$ were found positive [16]. EITB assay was also used in a recent survey performed in Antsirabe hospital (highlands) amongst suspected NCC patients. The EITB positive rate was $14,8 \%$ [17]. These data rank Madagascar as a country highly endemic for cysticercosis with major implications in public health

\section{Diagnosis \\ Laboratory tests}

The main clinical laboratories in Antananarivo use indirect hemagglutination, and commercial or in-house Immunoenzymatic assays for serological diagnosis of cysticercosis. The reference laboratory in Madagascar is hosted at the Pasteur Institute of Madagascar in Antananarivo (IPM). The Cysticercosis Unit of IPM developed and implemented serology tests applicable to epidemiological surveillance and diagnosis of

Figure 3. Extraction of cysts from a pig carcass (Pasteur Institute of Madagascar, 2009).

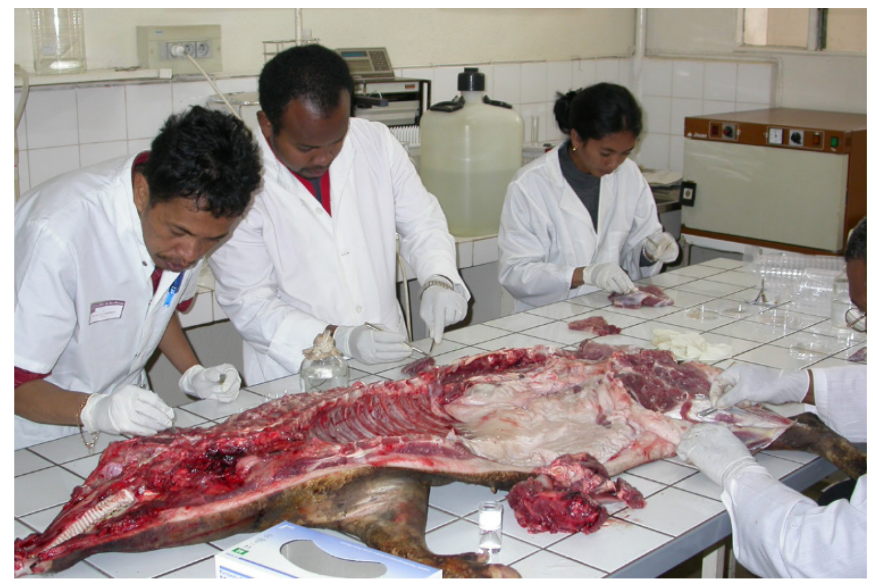


cysticercosis in the Malagasy population: an ELISA test was used for screening and EITB used for confirmatory testing [18]. Both tests use a Lentil lectin column purified glycoprotein fraction prepared from pig (Figure 3). The ELISA has been adapted from Diwan [19] and Michault [20]. It has a cut-off value fixed at 0.4 but has shown insufficient specificity $[6,21]$ justifying a confirmation with EITB, which shows improved specificity. The EITB test developed at IPM (Figure 4) is adapted from the Center for Diseases Control (CDC) EITB with some modifications [22,23]. Two specific bands (13 and $14 \mathrm{kDa}$ ) have been identified as significant markers of the cysticercus in an active (vesicle) stage of the infection when cestocidal treatment is strongly indicated. The same bands may on the other hand be absent at early (cyst) as well as late (calcified) stages of the infection [22-24]. In a study conducted amongst 256 children, 13,14 and $18 \mathrm{kDa}$ bands were significantly more frequently detected in sera of epileptic children than in sera of controls [25]. The B158/B60 Ag-ELISA [26-28] was originally implemented at IPM in 2010. First evaluations reported increased specificity and sensitivity, especially in single-cyst carriers who were misdiagnosed by the routine antibody ELISA ( $73 \%$ vs. $17 \%$, respectively, in patients with epidemiological, clinical and CT-Scan features compatible with NCC) [29]. Real time PCR was developped in Madagascar based on T. solium COX1 gene detection for diagnosis on cerebrospinal fluid (CSF). This technique was compared with the EITB also perfomed on CSF. It was found that $80 \%$ of patients with seizures and scanographic abnormalities were positive for PCR and/or EITB conducted in CSF. However, patients with seizures but with negative CTscan, showed $37 \%$ and $56 \%$ positivity for PCR and EITB in Cerebrospinal fluid (CSF), respectively [14]. However, nucleic acid amplification tests are unaffordable for most Malagasy patients and only available in specialized laboratories in Antananarivo. Currently, they are not in use for routine detection of the parasite but are used mostly for research.

The lack of ante-mortem diagnostic tools for porcine cysticercosis renders the evaluation of its prevalence difficult. Tongue palpation is specific but has a poor sensitivity ( $20 \%)$. Serological tests detecting antigens or antibodies seem to be promising for the diagnosis of CC in pigs. PCR is used to detect pathogens especially in industrialized countries but its performance for the diagnosis of porcine cysticercosis had not yet been evaluated. Therefore, the performance of PCR and Antibody ELISA assays has been evaluated by the IPM on 67 pig serum samples. Results indicate that ELISA on pig serum samples shows high sensitivity and good specificity while the PCR has a high specificity but a low sensitivity [30]. The

Figure 4. Homemade immuno-electro-transfer-blot (Pasteur Institute of Madagascar, 2009).

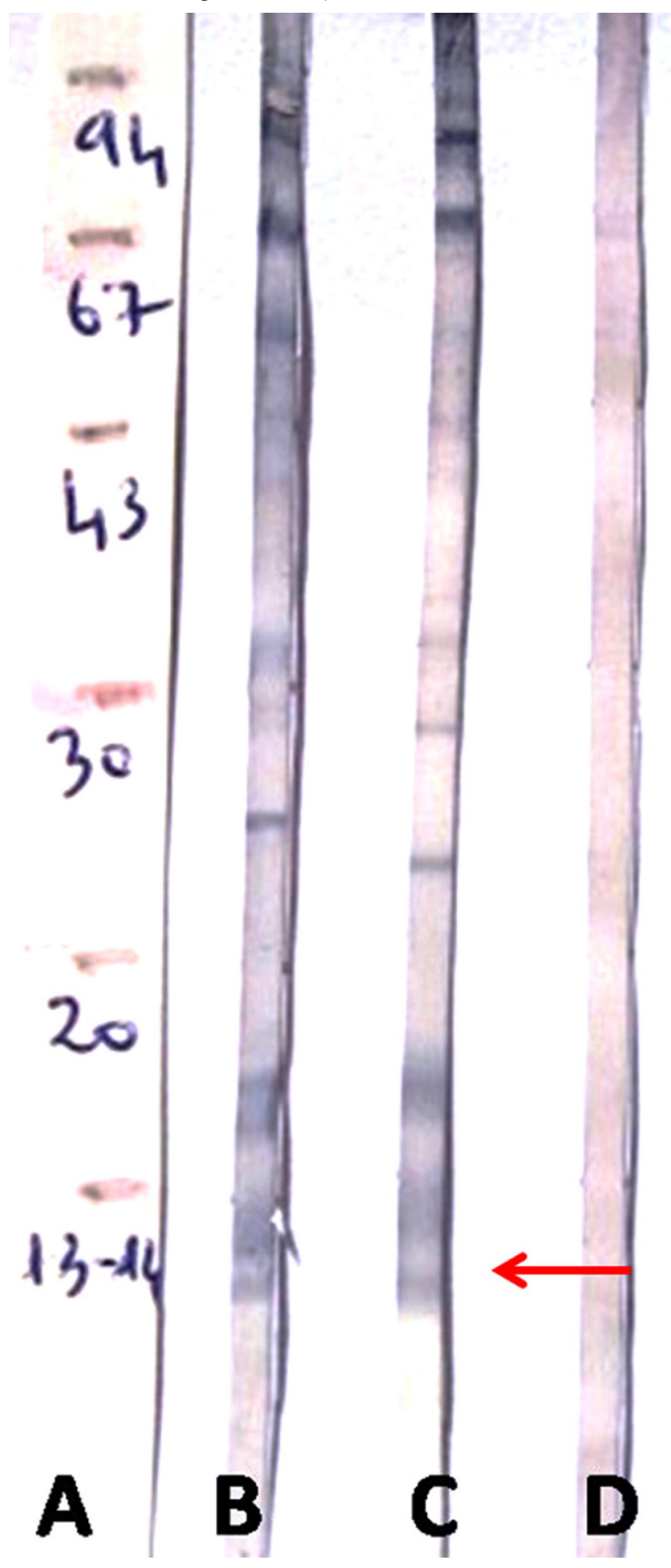

A: molecular weight marker (kDa); B: presence of 13 et $14 \mathrm{kDa}$ specific bands which may indicate active cysticercosis (red arrow); C: positive control; D: negative control. 
B158/B60 Ag-ELISA [27,28,31] was tested in Madagascar on swine sera. It showed a better performance both in terms of sensitivity and specificity than the Antibody ELISA test for the diagnosis of swine CC (unpublished data).

\section{Ongoing developments of Diagnostic tools of} Cysticercosis in Madagascar

From 2012 to 2017, a multidisciplinary-research project was conducted to improve the $\mathrm{CC}$ diagnosis: a molecular LAMP-test (loop-mediated isothermal amplification) based on the Cox-1 gene amplification was developped at the Pasteur Institute of Madagascar but its sensibility was bellow the RT-PCR used on-site $51 \%$ vs. 76.6\%). Production of recombinant specific glycoprotein (GP8V2, GP14 and GP18) was implemented to improve the performance of the available tests but also to design immunochromatographic rapid tests [32]. A bio-guided identification of new proteins in cysticercus fluid enabled the Pasteur Institute team to identify 18 new proteins of interest, nine were selected for further development [33].

\section{CT-scan in Madagascar}

Neuroimaging with CT or MRI is the most used method of diagnosis of NCC. Several CT-scans are available in Madagascar. They have allowed the characterisation of the main clinical presentations of NCC in the country. From May 1991 to November 1993, the Diagnostic Center of Antananarivo (Anosivavaka - Ambohimanarina district), diagnosed 135 cases of NCC: $40 \%$ of the cases had active lesions, $60 \%$ had sequelae [10]. Solitary cysticercus granuloma in the brain parenchyma accounts for most of the cases of NCC 5 (Figure 5). Other locations such as, meningeal or intraventricular NCC, are rarer. CT is very sensitive for the diagnosis of small intra-parenchymal lesions. However, the specificity is lower in view of a broad

Table 2. Diagnosis score for neurocysticercosis as proposed by Lesbobes et al. (1994) [10].

\begin{tabular}{lc}
\hline Criterion & Value \\
\hline Endemic area & 1 \\
Headache & 2 \\
Subcutaneous nodule or calcification & 1 \\
Epilepsy & 4 \\
Positive blood serology (ELISA or WB) & 2 \\
Positive CSF serology (ELISA or WB) & 4 \\
CT-Scan typical patterns & 7 \\
Major alcoholism & -1 \\
Score $\geq \mathbf{8}$ & Suspicion of \\
& neurocysticercosis \\
\hline
\end{tabular}

Figure 5. Brain CT-scan showing a single ring enhancing lesion related to neurocysticercosis.

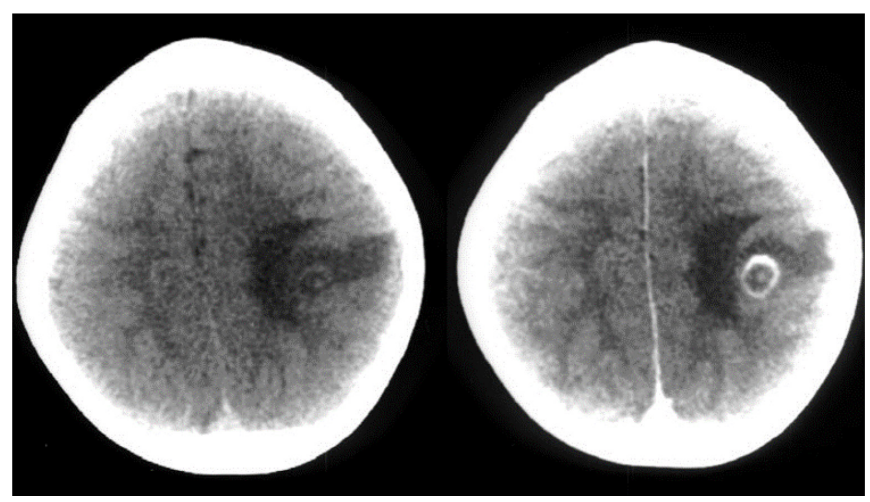

range of differential diagnosis (tuberculoma, toxoplasmosis, brain tumor). In addition, some cases may not be detected leading to false-negative $\mathrm{CT}$ results [14]. CT-Scan is no more the sole method used to assess the location in the brain of a T. solium cyst. MRI was implemented in 2015. Therefore, both remains unaffordable for most Malagasy patients who live far below the poverty line. The current price of a cerebral CT-scan in Madagascar is about 77 USD, 1.3 times the theoretical national minimum monthly income (59 USD). Furthermore, MRI is currently only available in Antananarivo.

Decision Tree for the diagnosis of human cysticercosis

As stated by Garg in 2004 [34], the available international diagnostic criteria given by Del Brutto et al. [2] are more suited for diagnosis of NCC in developed countries where it is uncommon, and where other infective conditions with similar clinical and radiological features, like CNS tuberculosis, are equally uncommon. Several attemps have been made in Madagascar to help physicians properly diagnose NCC. A first diagnostic tree was proposed in 1994 [10] by Lesbobes et al. (Table 2). It took into account epidemiological, clinical, imaging and laboratory data. A score above eight enabled the physician to suspect NCC.

Rakotomalala proposed a decision tree for pediatricians based on the economic resources of the patients [10]. In 2008, a collaborative work between IPM and the Neurology Unit of the Befelatanana Hospital published a diagnosis tree adapted to the Malagasy population [35]. This tree was adapted with the integration of the antigen ELISA $[27,28]$ that was implemented at IPM [29,36]. Its aim was to help physicians find the cause of a first onset of seizures taking into account not only medical patterns but also 
tests availability and financial considerations (Figure $6)$.

\section{Clinical features \\ Epilepsy}

About $90 \%$ of people with epilepsy live in developing countries, where the prevalence of the disease is high and the treatment gap (the ability to institute and maintain appropriate treatment) is large. This treatment gap was estimated to be over $92 \%$ in Madagascar [37], partly because of the poor availability and high cost of medication. Epilepsy is a health concern in Madagascar in both urban and rural settings. A recent study in the Boeny area stated that $12 \%$ of the outpatients coming to a primary care health center for neurological disorders had epilepsy [38]. People with epilepsy in low-income countries often prefer to put their trust in traditional healers rather than in modern medical care. In Madagascar, popular attitudes towards epileptic patient remain contradictory [39]. Christian camps offer an alternative option for people who are not willing or able to access medical services and, particularly, those who view epilepsy as the manifestation of an evil possession according to their religious beliefs. The treatment consists of prayers and exorcisms twice daily and the patients may be kept in solitary confinement [40].

Neurocysticercosis is a leading cause of seizures and epilepsy in the developing world, affecting children and adults. Many reports described cysticercosisassociated epilepsy in Madagascar. A case control study has been carried out in 1997. Patients over 15 years with late-onset epilepsy were serologicaly (blood and CSF EITB) compared to non-epileptic controls. The population-attributable risk of cysticercosis in lateonset epilepsy was $22.3 \%$ for the blood seropositive patients to $17.6 \%$ for CSF seropositive patients [41]. Another study reported $50 \%$ of serologically positive patients out of 113 epileptic adults admitted at Cenhosoa Hospital [10].

Pediatricians of the Cenhosoa hospital noted that epilepsy was present in over $80 \%$ of the cases of NCC [10]. They also encountered a few cases of subcutaneous and NCC in children less than 2 years. Electroencephalogram is a helpful diagnostic method in pediatricians since it helps to exclude some differential diagnosis, including spasmophylia [6]. The evolution of pediatric NCC is highly variable, from complete latency to severe encephalopathy with psychomotor regression [42].

Tsaralalana Mothers \& Children's Hospital is a pedriatric hospital in Antananarivo. Among 1800 children hospitalized in 1992, $108(6 \%)$ were clinically suspected of NCC. Among these, 28 children (25\%) were found serologicaly positive by ELISA and 9 were confirmed by EITB. Most of the clinical features were neurological: seizures, headache sassociated with eye impairement [10]. Rakotomalala [10] conducted a retrospective survey in Soavinandriana Hospital in 1991. A total of 231 epileptic children were included, aged 6 months to 15 years with epilepsy that could not be attributed to another cause. The seroprevalence was $48.9 \%$ (ELISA \pm EITB). Signs associated with epilepsy that increased the risk of having a positive serology were eosinophilia and the existence of an abnormal EEG (prevalence $62.5 \%, \mathrm{p}<0.05$ ).

Neurocysticercosis can be considered the main cause of secondary childhood epilepsy in Madagascar being one of the most important foci in the world $[41,43,44]$.

\section{Ocular cysticercosis}

In Madagascar, occular locations of cysticercosis are not frequent $(5 \%)$ and are focused primarily in the vitreous humour [45] and retina [10,46]. Diagnosis relies on serology that uses ELISA and EITB to detect circulating antibodies in the acqueous humor. Authors

Figure 6. Decision tree for the diagnosis of neurocysticercosis in Madagascar proposed by Carod et al. [36].

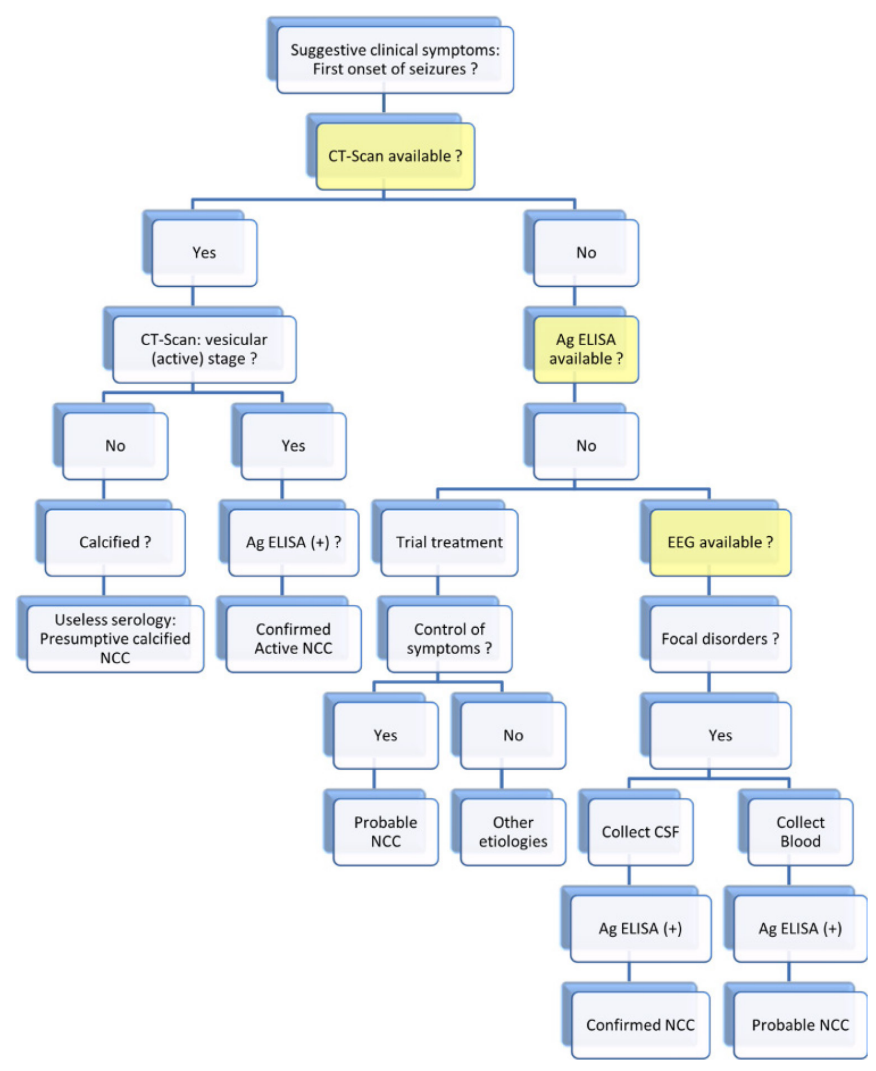


highlighted the interest of surgical treatment [45]. Since cysticercosis may, in rare cases, involve the retina, patients should be examined for the presence of retinal lesions before initiating therapy for neurocysticercosis. If such lesions are visualized, the need for anticysticeral therapy should be weighed against the possibility of retinal damage caused by anti-helminthic-induced changes to the retinal lesion. In Madagascar, this recommendation is not followed.

\section{Cutaneous cysticercosis}

Cutaneous cysticercosis (CC) in humans usually presents as asymptomatic subcutaneous nodules. It may occur as an isolated feature or as part of disseminated cysticercosis. Malagasy patients often ignore those nodules, which may be associated with NCC. Clinical examination is not specific. In a study conducted in 2006, out of 25 suspected cases, only five were diagnosed as CC. Diagnosis was made by biopsy of subcutaneous nodules [47] (Figure 7).

\section{$\underline{\text { Rare localizations }}$}

Some limited cases of atypical localizations have been described including bronchial [48], breast [49] and renal cysticercosis as a cause of extramembranous glomerulonephritis [50].

\section{Prevention and policy}

Taenia solium cysticercosis is a zoonosis of public health importance in Madagascar where the disease is endemic, with significant economic impacts on human health and the swine industry. Several gaps remain in the epidemiology of the parasite and the strategies of control in developing countries. In accordance with the government priorities and to improve the health of the population, the Malagasy Ministry of Health and Family Planning has defined a national policy [51] against cysticercosis and a specific preventive program [52]. This project followed WHO reports [53] and action considering NCC as an eradicable disease. It took into account all the biological and epidemiological data available. Its general objective was to reduce by $10 \%$ the overall prevalence of cysticercosis in Madagascar by 2015 . The intermediate objectives were to reduce by half the complications of cysticercosis and to obtain $50 \%$ of exposed population's compliance with latrine use. Specific objectives have been added: to improve the competence of $80 \%$ of all health workers in endemic areas, to ensure the supply of anthelmintic drugs to all health centers of the 33 endemic districts, to develop a database management system to store and update all epidemiological and clinical data on cysticercosis and to establish a multi-sectoral structure for hygiene and sanitation promotion.

Practical actions have been taken in 2011. Their goal was to screen a maximum number of patients in the capital for cysticercosis $[54,55]$. The screening took place at the Antananarivo University Center for Public Health (EUSSPA). Of the 500 screened patients for cysticercosis between December 2011 and June 2012, 353 people were found seropositive for $T$. solium and they were proposed a treatment [55]. In addition, educational tools such as a book for children have been developed in 2009 and medical conferences and their respective $\mathrm{CD}$ recording have been distributed to medical doctors and familly physicians throughout the island thanks to the contribution of "Les Confrères de Mada": a medical association in Madagascar [36]. Audio messages on Cysticercosis are regularly broadcasted such as the one with Pr Andriantseheno Marcellin in early January 2010. Not to mention, the national press releases that cover messages and events on the topic.

One significant gap in the control of the cysticercosis is the weak veterinary approach. The biggest dilemma officials have to face is the considerable corruption of meat inspectors and veterinarians who do not condemn most of the contaminated meat. This undestroyed meat is for them a significant source of revenue. Minced meat processing is one of the common ways butchers may use in Madagascar to hide the disease in meat for sale. In addition, Madagascar has only 300 veterinarians for a $585,040 \mathrm{~km}^{2}$ territory [56]. A multidisciplinary group of scientists proposed an action plan to fight the disease

Figure 7. Extracted cyst from a cutaneous suspected lesion: case of cutaneous cysticercosis.

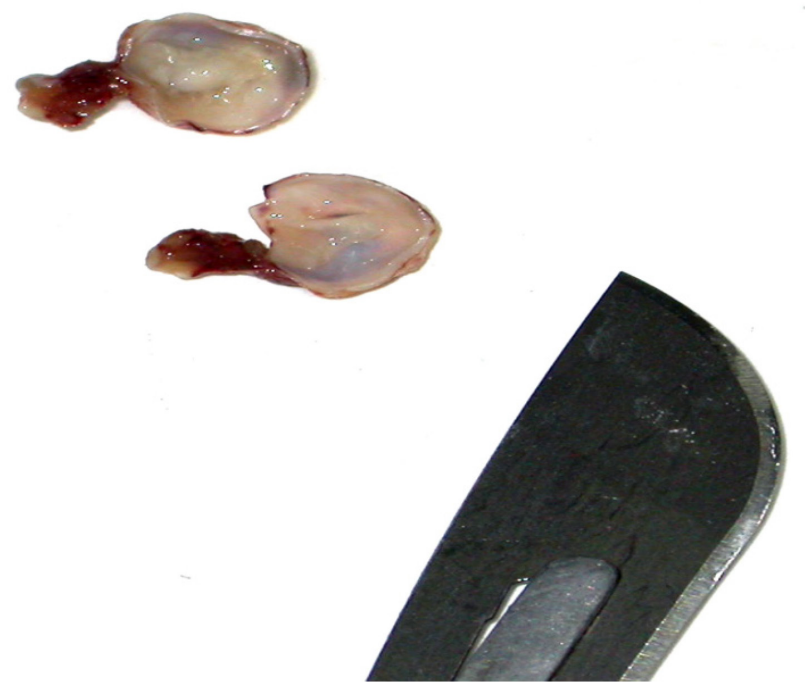


mostly at the veterinary level [5]. The authors invited the authorities to implement a strategic framework to control swine CC based on three objectives: 1. to develop a veterinary immunochromatographic assay to screen cysticercosis on live pigs, 2. to publish a good practice guidance booklet on swine breeding in Madagascar adapted to local conditions and 3. to build a recognized quality system to sustain consumers' confidence.

Furthermore, since human tapeworm carriers are the source of both human and swine cysticercosis, mass praziquantel treatment of children can reduce the tapeworm reservoir [5,57]. More than one million school-aged children have already been treated by praziquantel in Madagascar between June and October 2008 (Figure 8). This was part of a WHO initiative schistosomiasis control programme that was supported by Merck KGaA [58]. In July 2014, WHO organized an expert meeting on cysticercosis where Madagascar was one of the 5 countries present that was willing to implement a $\mathrm{CC}$ control/elimination program (other countries were Brasil, China, Vietnam and Ivory Coast) [59]. In September 2014, a multisectoral platform was initiated by WHO at the international and national level with the establishment of a national committee for tackling taeniasis / cysticercosis involving human health (Ministry of Public Health, Department of NTDs), animal health (Ministry of Livestock) and various research institutions (Pasteur Institute of Madagascar and CIRAD). The question that remains is: did this massive praziquantel administration have any impact on the prevalence of Teniasis and Cysticercosis? To answer this question, a pilot project was set up between 2015 and 2017, in the district of Antanifotsy (Highlands) to evaluate the effectiveness of a 3-round mass treatment campaign with Praziquantel. The general objective is to reduce the prevalence of taeniasis to less than $1 \%$ in the targeted population. The project includes a massive population education campaign $[60,61]$.

\section{Discussion and conclusions}

The World Health Organization (WHO) has listed neurocysticercosis as one of the neglected tropical disease. It estimates that about 50 million people worldwide have neurocysticercosis and that it causes about 50,000 deaths each year. This review demonstrated the high burden of cysticercosis and neurocysticercosis in Madagascar. Cysticercosis is considered an eradicable disease. Although theoretically feasible, overall wealth, hygiene and education level are not only very low but are even
Figure 8. Massive praziquantel treatment amongst Malagasy schoolchildren between June and October 2008. May it have an impact on cysticercosis epidemiology? (From: Merck KGaA, https://www.merckgroup.com/en).

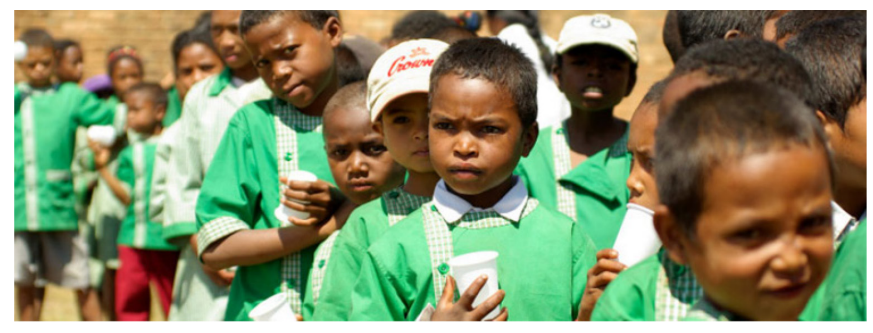

decreasing in Madagascar as a result of the political instability of the previous years. Preventing the pigs from roaming and emphasizing the systematic use of latrines are the key factors to interrupt the parasitic life cycle. The contribution of all sectors is required including a substantial fight against corruption at all levels of the chain. In addition, laboratory access for the diagnosis is very limited throughout the island and the sole current available option is the antibody detection in Antananarivo, which is obviously inadequate for single cyst carriers, which include the vast majority of patients in Madagascar. Promising issues are the development of an affordable and rapid antigen detection strip in order to provide human and swine reliable point of care or penside diagnosis access to the most remote areas of the big island, and to assess the impact of preventive chemotherapy with praziquantel on the epidemiology of cysticercosis.

\section{Acknowledgements}

To J. Michael Miller, Ph.D., D (ABMM), Director, Microbiology Technical Services, LLC (Dunwoody, GA, USA) for his careful proofreading and his corrections to the text. To J. Razahimahefa, MD, Neurology Unit, University Hospital Center, Antananarivo, Madagascar, for his contributions to the text. To all the staff of the Cysticercosis Unit and the Pathology Unit of the Pasteur Institute of Madagascar.

\section{References}

1. Singh G, Burneo JG, Sander JW (2013) From seizures to epilepsy and its substrates: neurocysticercosis. Epilepsia 54: 783-792.

2. Del Brutto OH, Nash TE, White AC, Rajshekhar V, Wilkins PP, Singh G, Vasquez CM, Salgado P, Gilman RH, Garcia HH (2017) Revised diagnostic criteria for neurocysticercosis. J Neurol Sci 372: 202-210.

3. Del Brutto OH (2014) Neurocysticercosis. Handb Clin Neurol 121: 1445-1459.

4. Yanagida T, Carod J-F, Sako Y, Nakao M, Hoberg EP, Ito A (2014) Genetics of the pig tapeworm in madagascar reveal a 
history of human dispersal and colonization. PloS One 9: e109002.

5. Porphyre V, Rasamoelina-Andriamanivo H, Rakotoarimanana A, Rasamoelina O, Bernard C, Jambou R, Cardinal E (2015) Spatio-temporal prevalence of porcine cysticercosis in Madagascar based on meat inspection. Parasit Vectors 8: 391.

6. Research group on cysticercosis (1994) Cysticercosis in Madagascar: consensus research. Arch Inst Pasteur Madagascar 61: 10-13. [Article in French].

7. Rasamoelina-Andriamanivo H, Porphyre V, Jambou R (2013) Control of cysticercosis in Madagascar: beware of the pitfalls. Trends Parasitol 29: 538-547.

8. Michelet L, Carod J-F, Rakontondrazaka M, Ma L, Gay F, Dauga C (2010) The pig tapeworm Taenia solium, the cause of cysticercosis: Biogeographic (temporal and spacial) origins in Madagascar. Mol Phylogenet Evol 55: 744-750.

9. Michelet L, Dauga C (2012) Molecular evidence of host influences on the evolution and spread of human tapeworms. Biol Rev Camb Philos Soc 87: 731-741.

10. Cysticercosis working Group (1994) Workshop on cysticercosis. Antananarivo, 4 December 1993. Proceedings and abstracts. Arch Inst Pasteur Madagascar 61: 2-61.

11. Migliani R, Rasolomaharo M, Rajaonarison P, Ravaoalimalala VE, Rabarijaona L, Andriantsimahavandy A (2000) Cysticercosis in the port of Mahajanga: more frequent than we thought! Arch Inst Pasteur Madagascar 66: 39-42. [Article in French].

12. Andriantsimahavandy A, Ravaoalimalala VE, Rajaonarison $P$, Ravoniarimbinina P, Rakotondrazaka M, Raharilaza N, Rakotoarivelo D, Ratsitorahina M, Rabarijaona LP, Ramarokoto CE, Leutscher P, Migliani R (2003) The current epidemiological situation of cysticercosis in Madagascar. Arch Inst Pasteur Madagascar 69: 46-51. [Article in French].

13. Razanamparany M, Aubry P (1999) Cysticercosis. Arch Pédiatrie Organe Off Sociéte Fr Pédiatrie 6 Suppl 2: 320-322. [Article in French].

14. Andriambololona R (2011) Associated risk factors of Cysticercosis in a rural town of the Haute Matsiatra, Madagascar. Pasteur Inst Madag. Available: http://www.pasteur.mg/IMG/pdf/COLLOQUE_CONJOINT_ PARASITO_VET_2011.pdf. Accessed: 11 June 2018. [Article in French].

15. Vigan Womas I (2017) Analysis of cultural and epidemiological factors that contribute to the spread of taeniasis / cysticercosis in the district of Ifanadiana (Ranomafana). Pasteur Inst Madag. Available: http://www.pasteur.mg/projets/analyse-des-facteurs-culturelset-epidemiologiques-qui-contribuent-a-la-propagation-de-lateniase-cysticercose-dans-le-district-de-ifanadianaranomafana/. Accessed: 2 May 2019. [Article in French].

16. Leutscher P, Andriantsimahavandy A (2004) Cysticercosis in peace corps volunteers in Madagascar. N Engl J Med 350: $311-$ 312

17. Zafindraibe NJ, Ralalarinivo J, Rakotoniaina AI, Maeder MN, Andrianarivelo MR, Contamin B, Michault A, Rasamindrakotroka A (2017) Seroprevalence of cysticercosis and associated risk factors in a group of patients examined at the Regional Referral Hospital in Antsirabe. Pan Afr Med J 28: 260.

18. Andriantsimahavandy A, Esterre P, Michault A, Raobelison A, Guyon P, Chabrier X, Lapprand M. (1996) Particularities of the immune response in neurocysticercosis. Arch Inst Pasteur Madagascar 63: 31-33. [Article in French].
19. Diwan AR, Coker-Vann M, Brown P, Subianto DB, Yolken R, Desowitz R, Escobar A, Gibbs CJ, Gajdusek DC (1982) Enzyme-linked immunosorbent assay (ELISA) for the detection of antibody to cysticerci of Taenia solium. Am J Trop Med Hyg 31: 364-369.

20. Michault A, Coubes P, Laporte JP, Bouillan-Linet E, Leroy D (1988) Diagnosis of cerebral cysticercosis on Réunion Island by an immuno-enzymological method (ELISA): comparison with X-ray computed tomography. Pathol Biol 36: 266-270. [Article in French].

21. Michel P, Michault A, Gruel JC, Coulanges P (1990) Serodiagnosis of cysticercosis by ELISA and western blot. Their value and limitations in Madagascar. Arch Inst Pasteur Madagascar 57: 115-142. [Article in French].

22. Simac C, Michel P, Andriantsimahavandy A, Esterre P, Michault A (1994) Value of immunodiagnosis by ELISA and Western blotting for the diagnostic and therapeutic management of neurocysticercosis. Arch Inst Pasteur Madagascar 61: 21-27. [Article in French].

23. Simac C, Michel $P$, Andriantsimahavandy A, Esterre $P$, Michault A (1995) Use of enzyme-linked immunosorbent assay and enzyme-linked immunoelectrotransfer blot for the diagnosis and monitoring of neurocysticercosis. Parasitol Res 81: 132-136.

24. Michault A, Rivière B, Fressy P, Laporte JP, Bertil G, Mignard C (1990) Contribution of enzyme-linked immunoelectrotransfer blot assay for the diagnosis of human neurocysticercosis. Pathol Biol 38: 119-125. [Article in French].

25. Grill J, Rakotomalala W, Andriantsimahavandy A, Boisier P, Guyon P, Roux J, Esterre P (1996) High prevalence of serological markers of cysticercosis among epileptic Malagasy children. Ann Trop Paediatr 16: 185-191.

26. Dorny P, Brandt J, Zoli A, Geerts S (2003) Immunodiagnostic tools for human and porcine cysticercosis. Acta Trop 87: 7986.

27. Rodriguez S, Dorny P, Tsang VCW, Pretell EJ, Brandt J, Lescano AG, Gonzalez AE, Gilman RH, Garcia HH (2009) Detection of Taenia solium antigens and anti-T. solium antibodies in paired serum and cerebrospinal fluid samples from patients with intraparenchymal or extraparenchymal neurocysticercosis. J Infect Dis 199: 1345-1352.

28. Gabriël S, Blocher J, Dorny P, Abatih EN, Schmutzhard E, Gabriël S, Blocher J, Dorny P, Abatih EN, Schmutzhard E, Ombay M, Mathias B, Winkler AS (2012) Added value of antigen ELISA in the diagnosis of neurocysticercosis in resource poor settings. PLoS Negl Trop Dis 6: e1851.

29. Carod J. F. (2012). The burden of neurocysticercosis: a multipurpose survey in Madagascar. Abstract Ref. O334 (oral session). European Congress of Clinical Microbiology and Infectious Diseases (ECCMID). London, U.K.

30. Ramahefarisoa RM, Rakotondrazaka M, Jambou R, Carod J-F (2010) Comparison of ELISA and PCR assays for the diagnosis of porcine cysticercosis. Vet Parasitol 173: 336-339.

31. Sato MO, Yamasaki H, Sako Y, Nakao M, Nakaya K, Plancarte A, Kassuku AA, Dorny P, Geerts S, Benitez-Ortiz W, Hashiguchi Y, Ito A (2003) Evaluation of tongue inspection and serology for diagnosis of Taenia solium cysticercosis in swine: usefulness of ELISA using purified glycoproteins and recombinant antigen. Vet Parasitol 111: 309-322.

32. Rahantamalala A, Vigan Womas I (2019) Diagnosis of Cysticercosis in Madagascar: Development and validation of molecular (LAMP-Cysti) and serological (Sero-Cysti) 
diagnostic tests for human and porcine cysticercosis. Pasteur Inst Madag. Available: http://www.pasteur.mg/projets/diagnostic-de-la-cysticercosea-madagascar-developpement-et-validation-de-tests-dediagnostic-moleculaires-lamp-cysti-et-serologiques-serocysti-pour-la-cysticercose-humaine-et-porcine/. Accessed: 5 January 2019. [Article in French].

33. Nativel $P$, Rahantamalala A, Ramiandrisoa $S$, Rasoamampianinaa V, Duchateau M, Chamot-Rooke J, Guebey R, Rasamoelina-Andriamanivo H, Jambou R (2016) Bio-guided identification of proteins for the diagnosis of cysticercosis in swine. Vet Parasitol 220: 23-27.

34. Garg RK (2004) Diagnostic criteria for neurocysticercosis: some modifications are needed for Indian patients. Neurol India 52: 171-177.

35. Andriantseheno LM, Rakotoson A, Razafimahefa J, Carod JF (2008) Cerebral cysticercosis in Madagascar. Proposal of a diagnostic algorithm. Médecine Trop Rev Corps Santé Colon 68: 640-642. [Article in French].

36. Carod J-F, Razafimahefa J., Andriantseheno L. M. (2010). Neurocysticercosis (Oral conference 01/08/2010). ClinicalBiological Meetings. In Les Confères de Mada (Ed.). Antananarivo, Madagascar: Joseph Ravoahangy Andrianavalona University Hospital.

37. Ratsimbazafy V, Andrianabelina R, Randrianarisona S, Preux P-M, Odermatt P (2011) Treatment gap for people living with epilepsy in Madagascar. Trop Doct 41: 38-39.

38. Gaud S, Sauvée M, Debouverie M (2014) Neurologic diseases in a rural tropical area: experience at a primary health care center in the Boeny region of Madagascar. Med Sante Trop 24 :312-316. [Article in French].

39. Andriantseheno LM, Rakotoarivony MC (2000) Sociocultural aspects of epilepsy in Madagascar. K.A.P. survey carried out in Antananarivo. Bull Société Pathol Exot 1990 93: 247-250. [Article in French].

40. Ratsimbazafy V, Rakotovao T, Marin B, Javerliat M, Preux PM (2012) The dangers of inadequate understanding of epilepsy in Madagascar. Lancet Neurol 11: 748-749.

41. Andriantsimahavandy A, Lesbordes JL, Rasoaharimalala B, Peghini M, Rabarijaona L, Roux J, Boisier P (1997) Neurocysticercosis: a major aetiological factor of late-onset epilepsy in Madagascar. Trop Med Int Health 2: 741-746.

42. Grill J, Pillet P, Rakotomalala W, Andriantsimahavandy A, Esterre P, Boisier P (1996) Neurocysticercosis: pediatric aspects. Arch Pédiatrie 3: 360-368. [Article in French].

43. Grill J, Rakotomalala W, Andriantsimahavandy A, Boisier P, Guyon P, Roux J, Esterre P (1996) High prevalence of serological markers of cysticercosis among epileptic Malagasy children. Ann Trop Paediatr 16: 185-191.

44. Debacq G, Moyano LM, Garcia HH, Boumediene F, Marin B, Ngoungou EB, Preux PM (2017) Systematic review and metaanalysis estimating association of cysticercosis and neurocysticercosis with epilepsy. PLoS Negl Trop Dis. 11: e0005153.

45. Auzemery A, Andriantsimahavandy A, Bernardin P, Queguiner P (1996) Intravitreous cysticercosis. Spontaneous course. Apropos of a case. J Fr Ophtalmol 19: 556-558. [Article in French].

46. Bernardin P, Auzemery A, Rabenantoandro C (1994) Ocular cysticercosis (O.C.) in Madagascar (apropos of 6 cases). Rev Int Trach Pathol Ocul Trop Subtrop Sante Publique 71: 103113.
47. Carod J. F. (2013). Contribution of serological and molecular assays for the diagnosis of subcutaneous cysticercosis. Abstract Ref P2300 poster session. European Congress of Clinical Microbiology and Infectious Diseases (ECCMID). Berlin, Germany.

48. Coulanges $\mathrm{P}$, Ramaholimihaso F, Randrianonimandimby J (1986) Cysticercosis in Madagascar (apropos of unusual bronchial localization). Arch Inst Pasteur Madagascar 52: 5368. [Article in French].

49. Rakoto-Ratsimba HN, Rabesalama SSEN, Razafimahandry HJC, Ranaivozanany A (2007) Case report of solitary breast cysticercosis in Madagascar. Médecine Trop Rev Corps Santé Colon 67: 179-180. [Article in French].

50. Rabenantoandro R, Rasoloarijaona L, Raharivelina C, Ralaifonenana J, Rasamindrakotroka J (1996) Extramembranous glomerulonephritis and cysticercosis. Santé 6: 254-257. [Article in French].

51. Ministry of Health, Family Planning and Social Protection of Madagascar (2007) Health sector development plan 2007$2011 . \quad$ Available: https://www.uhc2030.org/fileadmin/uploads/ihp/Documents/ Country_Pages/Madagascar/MadagascarPDSS_25mars_2007. pdf. Accessed: 2 November 2018. [Article in French].

52. Ministry of Health, Family Planning and Social Protection of Madagascar (2005) National Cysticercosis Control Policy. Available: http://pdfmedarticles.com/s/sante.gov.mg1.html. Accessed: 14 October 2014. [Article in French].

53. World Health Organization Geneva (2002) Control of neurocysticercosis. Provisional agenda item 13.18. Available: http://apps.who.int/gb/archive/pdf_files/WHA55/ea5523.pdf. Accessed: 30 October 2014.

54. Radasimalala V (2011) Madagascar: Health - rush to screen for cysticercosis. Available: http://fr.allafrica.com/stories/201112191185.html. Accessed: 30 October 2014. [Article in French].

55. Vonjy R (2013) Madagascar: Cysticercosis victims recalled. Available: https://fr.allafrica.com/stories/201301161108.html. Accessed: 30 October 2014. [Article in French].

56. Vonjy R (2014) Meats escape veterinary control. Available: https://fr.allafrica.com/stories/201402120690.html. Accessed: 30 October 2014. [Article in French].

57. Costard S, Porphyre V, Messad S, Rakotondrahanta S, Vidon H, Roger F, Pfeiffer DU (2009) Multivariate analysis of management and biosecurity practices in smallholder pig farms in Madagascar. Prev Vet Med 92: 199-209.

58. World Health Organization Geneva (2008) Schistosomiasis control in Madagascar - Newsletter. Available: http://www.who.int/neglected_diseases/integrated_media/inte grated_media_schistosomiasis/en/. Accessed: 2 November 2014.

59. World Health Organization Geneva (2014) Assembling a framework for intensified control of taeniasis and neurocysticercosis caused by Taenia solium. Available: https://apps.who.int/iris/bitstream/handle/10665/153237/9789 241508452_eng.pdf. Accessed: 3 November 2014.

60. Pasteur Institute of Madagascar (2017) Evaluation of the impact of a mass treatment campaign in the Antanifotsy district to fight against taeniasis / cysticercosis. Available: http://www.pasteur.mg/projets/evaluation-de-limpact-dunecampagne-de-traitement-de-masse-des-populations-dudistrict-dantanifotsy-pour-lutter-contre-la-teniasecysticercose/. Accessed: 1 May 2019. [Article in French]. 
61. World Health Organization Geneva (2016) Madagascar: put an end to pork tapeworm. Available: https://www.who.int/fr/news-room/featurestories/detail/madagascar-halting-pig-transmitted-tapeworm. Accessed: 1 May 2019.

\section{Corresponding author}

Jean-François Carod, Pharm D, MSc.

Clinical Biologist-Head of Unit and Medico-tech departments

West French Guiana Hospital Center, B.P 245

97393 Saint-Laurent du Maroni Cedex

French Guiana

Tel: 00 (594) 594348725

Email: jf.carod@ch-ouestguyane.fr

Conflict of interests: No conflict of interests is declared. 